\title{
Aspartic Acid Side Chain Effect-Experimental and Theoretical Insight
}

\author{
Marko Rožman \\ Laboratory for Chemical Kinetics and Atmospheric Chemistry, Ruđer Bošković Institute, Zagreb, Croatia
}

Gas-phase H/D exchange and density functional theory study of the Asp and Glu side-chain carboxylic group intrinsic reactivity is reported. H/D exchange site specific treatment and some additional theoretical calculations showed that a side-chain carboxylic group may initiate proton transfer along with bond formation to one of its oxygens, i.e., possibility to initiate selective of cleavage peptide bond ("aspartic acid effect"). That finding is used to select aspartic acid cleavage mechanisms (side-chain proton transfer either to backbone carbonyl or to amide nitrogen) for further computational study. B3LYP/6-31G(d) and G3(MP2)//B3LYP potential energy profiles of both mechanisms on a model system $\mathrm{CH}_{3} \mathrm{CO}-\mathrm{Asp}-\mathrm{NHCH}_{3}$ were constructed. Although energy employed in low-energy collision induced dissociation suffices for both mechanisms thresholds, energy transferred to specific modes suggests a complex one-step mechanism of proton transfer (from the side-chain carboxylic group to the backbone amide group), bond formation (between deprotonated carboxylic group and carbon atom of the backbone carbonyl), and peptide bond cleavage as favorable. (J Am Soc Mass Spectrom 2007, 18, 121-127) (C) 2007 American Society for Mass Spectrometry

$\mathrm{N}$ umerous studies [1-9] have shown residual specific cleavage especially at Pro, Asp, Glu, and oxidized Cys amino acid residues. In the mass spectra of peptides (with no mobile protons) containing Asp, Glu, and oxidized Cys, selective cleavage of the amide bond C-terminal is dominant (the "aspartic acid effect") and often results in loss of sequence informative fragments side-chain carboxylic group esterification, suspended dominant cleavage, and provided a proof that the carboxylic group plays the key role in the selective cleavage process [9]. It is shown that aspartic acid effect in peptides predominates when the number of ionizing protons does not exceed the number of basic residues and, also, that cleavage occurs without involvement of the ionizing proton [5, 9].

Several studies [3-5] proposed and discussed schematic mechanisms of the selective Asp cleavage, Scheme 1. Yu et al. [3] suggested a mechanism with salt-bridge intermediate (Scheme 1a). Price et al. [4] modified Yu's mechanism, taking into account necessity for $-\mathrm{COO}^{-}$group stabilization by protonation of Arg side-chain (Scheme 1b). On the other hand, it is difficult to stabilize reactive acylium ion, i.e., Price's mechanism product. Thus, Gu et al. [5] suggested another extension of Yu's model (Scheme 1c).

A step towards revealing energetic and mechanistic features of the fragmentation pathway was the investigation of protonated Arg- $\mathrm{Asp}-\mathrm{NH}_{2}$ [7]. It indicated a

Published online October 17, 2006

Address reprint requests to Dr. Marko Rožman, Laboratory for Chemical Kinetics and Atmospheric Chemistry, Ruđer Bošković Institute, Bijenička 54, HR-10002 Zagreb, Croatia. E-mail: marko@irb.hr mechanism (Scheme 1d) as the energetically most favorable and suggested that an energetically close mechanism (Scheme 1e) should be also considered. Although Paizs et al. [7] took into account mechanisms A, B, D, and $\mathrm{E}$, they did not consider mechanism C. Moreover, they analyzed the dipeptide combination Arg-Asp, which is not likely to exist in experiments that use trypsin for enzymatic digestion. Although investigated mechanisms are probably very similar in Asp-Arg combination, there is a question whether mechanism $\mathrm{E}$ yields the same product or the salt bridge conformation is just an intermediate in mechanism D.

Recently, it was demonstrated that gas-phase H/D exchange can be used to investigate the aspartic sidechain effect [9]. The experiment demonstrated carboxylic side-chain group hydrogen exchange in the absence of a mobile proton. This result supports the idea of a "locally" mobile proton able to initiate fragmentation.

Novel use of H/D exchange and interest to understand the aspartic side-chain effect motivated this study. The first part is focused on the use of gas-phase H/D exchange as probe for a "locally" mobile proton. Information obtained from gas-phase site-specific H/D exchange is used to select most probable mechanisms. In the second part, structural details and energetics of these mechanisms are examined by high level theoretical calculations on the $\mathrm{CH}_{3} \mathrm{CO}-\mathrm{Asp}-\mathrm{NHCH}_{3}$ model system.

\section{Experimental}

The H/D exchange experiments were performed in a 3 $\mathrm{T}$ Fourier transform ion cyclotron resonance (FTICR) mass spectrometer (Extrel FTMS 2001, Madison, WI). 
a)

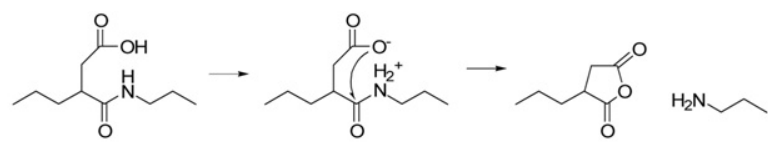

b)

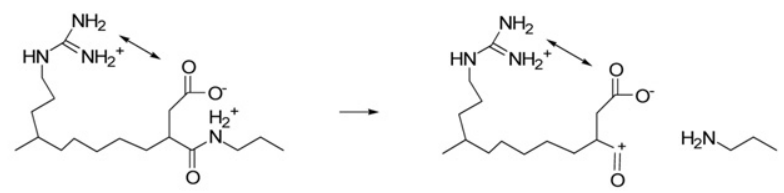

c)
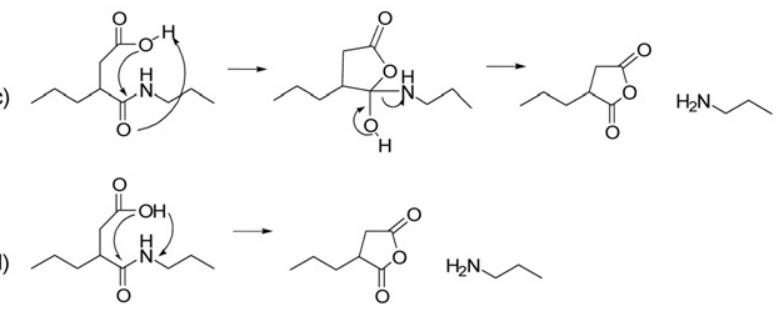

e)

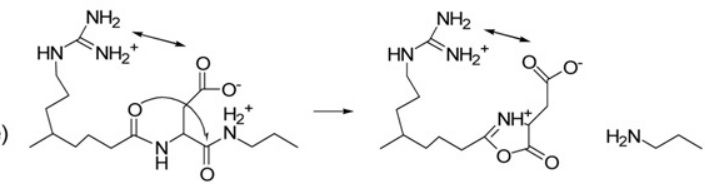

Scheme 1

Asp and Glu (Fluka, Buchs, Switzerland) MALDI samples were prepared with a standard dried-droplet procedure using 2,5-dihydroxybenzoic acid (DHB) as matrix. Protonated ions were generated in the ICR cell with two consecutive $337 \mathrm{~nm}$ laser pulses from a nitrogen laser (VSL 337 NSD, LSI Laser Science, Newton, MA). After formation, all ions were allowed to cool for $0.5 \mathrm{~s}$ and then the monoisotopic ions were isolated with a SWIFT waveform. These ions were then allowed to react with a background pressure of a deuterium donor. The deuteration reagent was $\mathrm{D}_{2} \mathrm{O}(99.8 \%$, Aldrich, Milwaukee, WI). The stabilized reagent gas pressure of $\sim 2$ $\cdot 10^{-5} \mathrm{~Pa}$ used in the exchange experiments was measured with a Bayard-Alpert type ionization gauge using parameterized response factors for calibration [10]. All experiments were performed at an ambient temperature of $300 \mathrm{~K}$. The experimental data were treated as if they referred to five independently exchanging sites. Site-specific reaction rate constants were determined by applying "probability" treatment as suggested in reference [11]. The curve fitting was done in Mathematica 4.0 (Wolfram Research, Champaign, IL).

Calculations for various structures were performed using B3LYP functional with 6-31G(d) basis set. Stationary points [i.e., the minima and transition states on the potential energy surface (PES)] were tested by harmonic frequency analysis. Transition-state structures were additionally tested by intrinsic reaction coordinate (IRC) analysis. Displayed energies were not corrected for zero point energies.

Final energetics of $\mathrm{H} / \mathrm{D}$ exchange complex were done at the B3LYP/6-311 ++ G(d,p) level to get more accurate comparison with previously obtained mecha- nism barriers [12]. Consistently, in those calculations, the $\mathrm{D}_{2} \mathrm{O}$ molecule was mimicked by $\mathrm{H}_{2} \mathrm{O}$.

Model system $\left(\mathrm{CH}_{3} \mathrm{CO}-\mathrm{Asp}-\mathrm{NHCH}_{3}\right)$ aspartic acid cleavage mechanism potential energy diagrams were additionally calculated with the G3(MP2)//B3LYP (G3MP2B3) computational protocol [13] to estimate the accuracy of the calculated B3LYP barriers. The relative barrier errors were up to $\sim 30 \mathrm{~kJ} \mathrm{~mol}^{-1}(0.3 \mathrm{eV})$, and the B3LYP/6-31G(d) treatment was considered acceptable for this kind of problem (low-energy CID). All calculations were performed using the Gaussian 03 [14] program package.

\section{Results and Discussion}

\section{H/D Exchange}

To properly test for locally mobile proton using H/D exchange, one has to consider influence of the deuterating agent on (1) the secondary structure of the analyte and (2) the side-chain carboxylic group H/D exchange mechanism. Concerning (1), it was recently shown [15] that in the interaction between protonated amino acid and water, $\mathrm{H} / \mathrm{D}$ exchange is favored over conformational changes; (2) study of H/D exchange mechanism showed that isotopic exchange of carboxylic hydrogen mainly occurs by barrierless "flip-flop" reaction, i.e., at a high exchange rate $[12,16]$. Moreover, reaction proceeds without influence of ionizing proton, and the deuterating agent is stabilized solely at one site. The same might be true for Asp and Glu side-chain carboxylic groups.

In the gas-phase $\mathrm{H} / \mathrm{D}$ exchange of $\mathrm{AspH}^{+}$and $\mathrm{GluH}^{+}$with $\mathrm{D}_{2} \mathrm{O}$, all five weakly-bound hydrogens get exchanged. The determined reaction rate constants for site-specific H/D exchange are shown in Table 1.

The rate constants indicate presence of two fast exchanging and three equivalent slowly exchanging hydrogens. In accordance with calculated structures of $\mathrm{AspH}^{+}$and $\mathrm{GluH}^{+}$(Figure 1), the two fast exchanging sites correspond to carboxylic groups and the three equivalent ones to protonated $\alpha$-amino group. Sitespecific kinetic studies [12, 17, 18] of aliphatic amino acids enable comparison of the exchange rates. The rate constant values are consistent with previous studies [12, 17], but some difference to those obtained by He et al. [18] exists in their magnitude (arising mainly from the pressure measurement). Comparing our exchange rates with those from previous studies, one may conclude

Table 1. Site-specific $H / D$ exchange rate constants $\left(\times 10^{-11}\right.$ $\mathrm{cm}^{3} \mathrm{~s}^{-1}$ molecules ${ }^{-1}$ ) for reaction of the studied protonated amino acids with $\mathrm{D}_{2} \mathrm{O}$

\begin{tabular}{lcl}
\hline Amino acid & $\mathrm{AspH}^{+}$ & $\mathrm{GluH}^{+}$ \\
\hline \hline$k_{1}$ & 11.4 & 6.15 \\
$k_{2}$ & 2.06 & 0.58 \\
$k_{3}$ & 0.6 & 0.3 \\
$k_{4}$ & 0.6 & 0.3 \\
$k_{5}$ & 0.6 & 0.3 \\
\hline
\end{tabular}




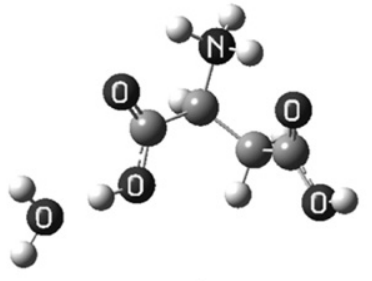

1

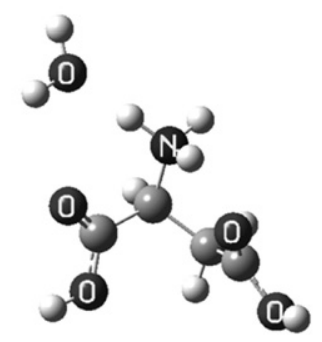

3

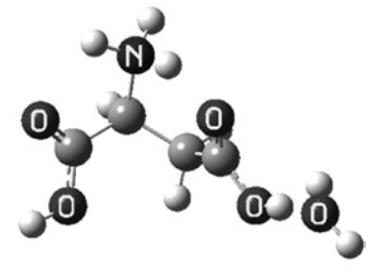

2

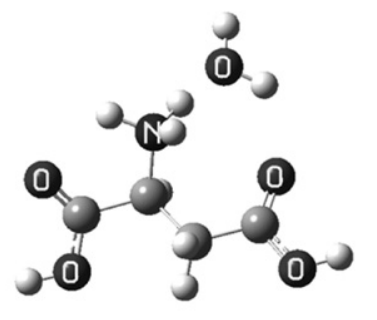

4
Figure 1. B3LYP/6-311 ++ G(d,p) $\mathrm{AspH}^{+}-\mathrm{D}_{2} \mathrm{O}$ complexes.

that the fastest exchange occurs at the carboxylic group, and the three equivalent sites correspond to the protonated $\alpha$-amino group. The remaining fast exchanging site would then be the side-chain carboxylic group. However, definite assignment of carboxylic groups needs additional arguments, vide infra.

Thus, the formation of H/D exchange reaction complexes was analyzed to assign the fast exchanging sites to corresponding carboxylic groups. First, the $\mathrm{AspH}^{+}$ and $\mathrm{GluH}^{+}$most stable structures were considered. Sun et al. [19] found the most stable conformation of $\mathrm{GluH}^{+}$ at the B3LYP/6-31 + G(d,p) level. Same conformation was reoptimized at the B3LYP/6-31G(d) level together with similarly formed $\mathrm{AspH}^{+}$. The structures are stabilized by two intramolecular hydrogen bonds, both involving protonated $\alpha$-amino group and carbonyl group oxygens. Previous investigations of H/D exchange on similar systems showed that, depending on direction of attack, during a few ps the deuterium donor stabilizes near the active/preferred site [11, 20]. In present systems, four such structures for each amino acid were identified starting from $\mathrm{AspH}^{+}$and $\mathrm{GluH}^{+}$ most stable structures. Since $\mathrm{AspH}^{+}$and $\mathrm{GluH}^{+}$formed "identical" complexes, only $\mathrm{AspH}^{+}-\mathrm{D}_{2} \mathrm{O}$ complexes are depicted at Figure 1.

In Complex $1 \mathrm{D}_{2} \mathrm{O}$ appears close to carboxylic group while in Complex $2 \mathrm{D}_{2} \mathrm{O}$ is close to $\beta$-carboxylic group (or to $\gamma$-carboxylic group in case of the $\mathrm{GluH}^{+}$). Complexes 3 and 4 are defined with $\mathrm{D}_{2} \mathrm{O}$ stabilized between the protonated $\alpha$-amino group and the $\beta$-carboxylic group (or $\gamma$-carboxylic group in case of the $\mathrm{GluH}^{+}$). Complexes 1 and 2 contribute only to exchange of their corresponding carboxylic group hydrogen ("flip-flop" mechanism [12,16] while Complexes 3 and 4 to the exchange of both the $\alpha$-amino hydrogens and corresponding carboxylic group hydrogen. Starting Com-
Table 2. The absolute energies (in $E_{\mathrm{h}}$ ) and relative stabilities (in $\mathrm{kJ} \mathrm{mol}^{-1}$ ) of $\mathrm{AspH}^{+}-\mathrm{D}_{2} \mathrm{O}$ and $\mathrm{GluH}^{+}-\mathrm{D}_{2} \mathrm{O}$ complexes

\begin{tabular}{|c|c|c|c|c|}
\hline \multirow{2}{*}{$\begin{array}{l}\text { Reaction } \\
\text { complex }\end{array}$} & \multicolumn{2}{|c|}{ B3LYP/6-31G(d) } & \multicolumn{2}{|c|}{$\begin{array}{c}\text { B3LYP/6-311 ++ } \\
\text { G(d,p) }\end{array}$} \\
\hline & $E$ & $\Delta$ & E & $\Delta$ \\
\hline $\mathrm{AspH}^{+}+\mathrm{D}_{2} \mathrm{O}$ & -588.927703 & 0 & -589.30806 & 0 \\
\hline $\mathrm{AspH}^{+}-\mathrm{D}_{2} \mathrm{O}(1)$ & -588.956877 & -76.6 & -589.33477 & -70.1 \\
\hline $\mathrm{AspH}^{+}-\mathrm{D}_{2} \mathrm{O}(2)$ & -588.955026 & -71.7 & -589.333062 & -65.6 \\
\hline $\mathrm{AspH}^{+}-\mathrm{D}_{2} \mathrm{O}$ (3) & -588.955808 & -73.8 & -589.334288 & -68.8 \\
\hline $\mathrm{AspH}^{+}-\mathrm{D}_{2} \mathrm{O}(4)$ & -588.954339 & -69.9 & -589.333246 & -66.1 \\
\hline $\mathrm{GluH}^{+}+\mathrm{D}_{2} \mathrm{O}$ & -628.224546 & 0 & -628.644955 & 0 \\
\hline $\mathrm{GluH}^{+}-\mathrm{D}_{2} \mathrm{O}(1)$ & -628.25276 & -74.1 & -682.670622 & -67.4 \\
\hline $\mathrm{GluH}^{+}-\mathrm{D}_{2} \mathrm{O}(2)$ & -628.250106 & -67.1 & -682.668272 & -62.1 \\
\hline $\mathrm{GluH}^{+}-\mathrm{D}_{2} \mathrm{O}(3)$ & -628.249624 & -65.8 & -682.668509 & -61.9 \\
\hline $\mathrm{GluH}^{+}-\mathrm{D}_{2} \mathrm{O}(4)$ & -628.24174 & -45.1 & -682.660325 & -40.4 \\
\hline
\end{tabular}

plexes 1 to 4 were optimized at the B3LYP/6-31G(d) level, while final energies and relative stabilities were obtained at the B3LYP/6-311 ++ G(d,p), Table 2 .

The H/D exchange rate depends mainly on the potential energy profile of the reaction [12]. Here, the greater stability of starting complexes correlates well with the observed higher exchange rate. Comparison of relative energies and exchange rates at the two carboxylic groups suggests a slower exchange for the side-chain carboxylic group hydrogen. According to the barrier of $104.6 \mathrm{~kJ}$ $\mathrm{mol}^{-1}$ (relative to initial starting complex) for H/D exchange in similar position [12], the $\mathrm{GluH}^{+}$Complex 4 stabilization of only $40.4 \mathrm{~kJ} \mathrm{~mol}^{-1}$ suggests lack of exchange, in agreement with observed experimental rate decrease ( $\alpha$-amino and $\gamma$-carboxylic group). Deuterium incorporation to $\mathrm{GluH}^{+} \alpha$-amino group proceeds through Complex 3 while $\gamma$-carboxyl deuteration is a result of "flip-flop" mechanism in Complex 2. Overall, H/D exchange of the $\mathrm{AspH}^{+}$and $\mathrm{GluH}^{+}$side-chain carboxylic hydrogen is mainly result of "flip-flop" mechanism, Scheme 2. That supports the possibility of a side-chain carboxylic group proton transfer, which initiates a simultaneous bond formation with one of its oxygens, i.e., existence of a locally mobile proton that may initiate fragmentation through mechanisms $\mathrm{C}$ or D.

\section{Aspartic Acid Effect Mechanism}

Recent studies $[1,7,9]$ showed that selective Asp cleavage mechanism is still uncertain and its energetics unknown. Thus, Herrmann et al. [9] discuss that it is not clear whether the mechanism involves proton transfer to the carbonyl oxygen (Scheme 1c) or to the amide nitrogen (Scheme 1d). To increase our understanding of the aspartic acid effect, mechanisms $\mathrm{C}$ and $\mathrm{D}$ were examined on a model system $\mathrm{CH}_{3} \mathrm{CO}-\mathrm{Asp}-\mathrm{NHCH}_{3}$. Mechanism E

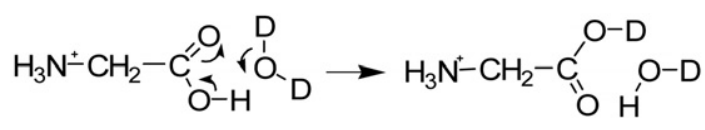

Scheme 2 


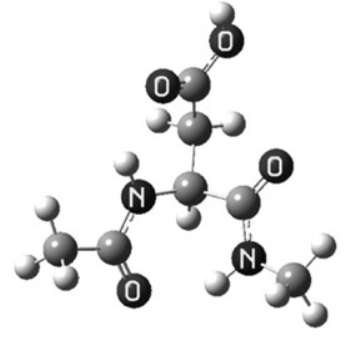

C-NNO

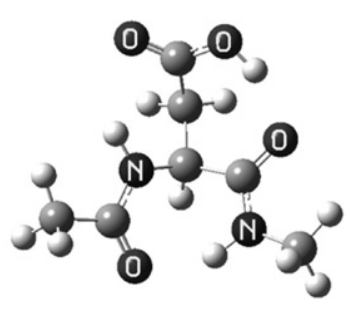

C-NN1
Figure 2. Conformers $\mathrm{C}-\mathrm{NN} 0$ and $\mathrm{C}-\mathrm{NN} 1$. Corresponding B3LYP/6-31G(d) energies and G3MP2B3 enthalpies are shown in Appendix Tables 1 and 2.

(Scheme 1e) was not considered because it requires assistance of an additional functional group (e.g., guanidino) to be able to form strong $\mathrm{H}$-bond(s). In that case we believe that intrinsic Asp side-chain effect is (in a way) hindered. Furthermore, it is shown that selective cleavage occurs despite lack of assisting group [5, 6, 9].

Previous structural calculations [9] on the same model system have shown conformer C-NN0 as a lowest energy structure, while our calculations show conformers C-NN0 and C-NN1 to be degenerate in energy, Figure 2. Structure C-NN1 represents starting conformation in mechanism $\mathrm{C}$. To properly simulate a cleavage effect, one has to consider both syn (NHNH or $\mathrm{NN}$ ) and anti (NHCO or NC) orientations of amidic hydrogens. Two possible orientations per two mechanisms yield four structures: C-NN1 (NN orientation in mechanism C), C-NC1 (NC orientation in mechanism C), D-NC1 (NC orientation in mechanism D), and D-NN1 (NN orientation in mechanism D). Although structure C-NN1 represents NC orientation, it is converted to NN orientation structure through transitionstate C-NN12. Here, is important to stress that comparison of relative stabilities of starting intermediates is not significant because that stability is not necessarily re- flected in a real system. It is reasonable to expect presence of syn and anti orientation in peptide ions undergoing MSMS. Also, low-energy CID is an energy rich process compared with the small energy difference $\left(\sim 15 \mathrm{~kJ} \mathrm{~mol}^{-1}\right.$ ) between conformers (except for DNN1), thus making conceivable that structures easily convert one to another.

The potential energy profiles, together with optimized structures for the mechanisms $\mathrm{C}$ (C-NN and C-NC) and D (D-NN and D-NC), are shown in Figures 3 and 4. Absolute energies $(E)$ and relative stabilities $(\Delta)$ of computed structures are given in Appendix Tables 1 and 2. Potential energy diagrams are obtained at the B3LYP/6-31G(d) level of theory and with the G3MP2B3 computational protocol. One may note that the B3LYP/6-31G(d) energies and especially dissociation thresholds are in good agreement with the G3MP2B3 enthalpy values. Final point (product) on potential energy profiles in all presented mechanisms represents dissociated fragments.

Mechanism $C$ is a two-step reaction, which begins with concerted proton transfer/bond formation in the transition-state C-NC12 (or C-NN12), respectively. Here, a proton is transferred from side-chain Asp carboxylic group to the backbone carbonyl group and, simultaneously, a bond between deprotonated carboxylic group and carbon atom of the backbone carbonyl is formed. Peptide bond cleavage occurs in the second reaction step, which represents proton transfer to the amide group. The corresponding transition-state CNC23 (or C-NN34), respectively, is associated with the energetically highest barrier. Additional points C-NN23 and C-NN3 (structures not shown in Figure 3) on mechanism C-NN potential energy profile represent rotation of amide methyl group needed to remove constrain for proton transfer.

On the other hand, mechanism D is a one step reaction that occurs through transition-state D-NC12 (or D-NN12). It involves proton transfer (from side-chain Asp carboxylic group to the backbone amide group),
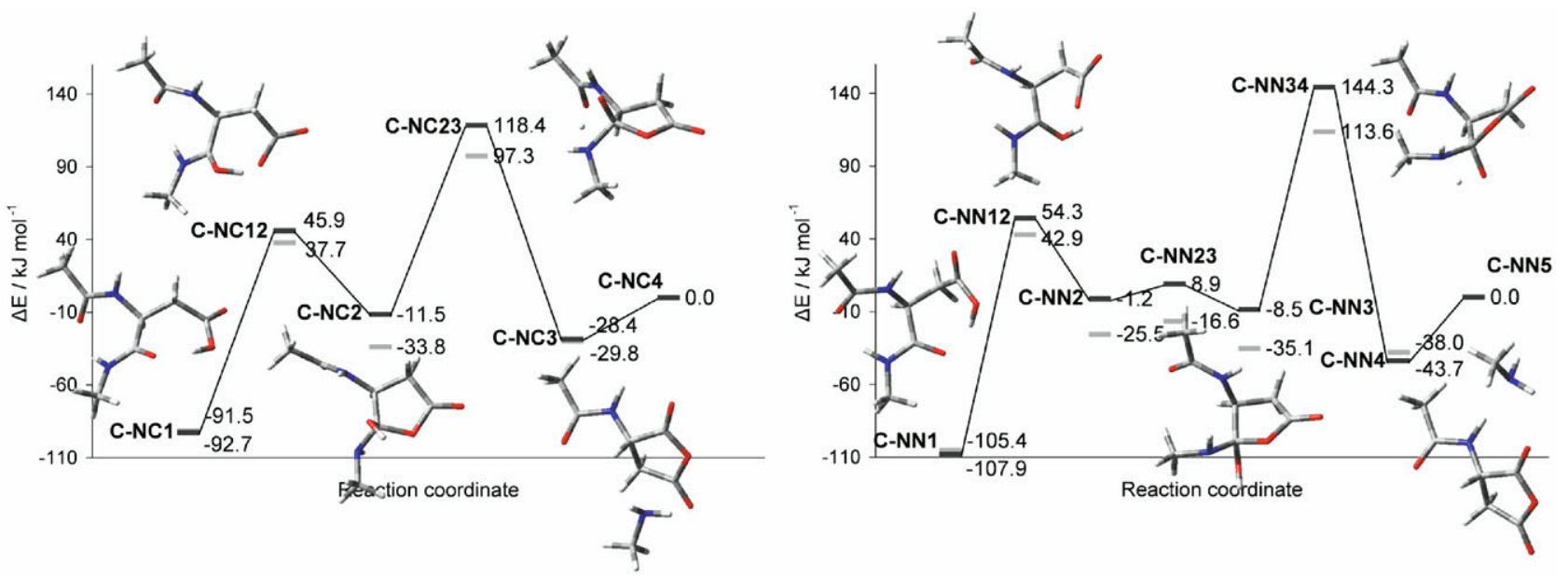

Figure 3. Schematic representation of the mechanisms C-NC and C-NN potential energy profiles. The relative energies and optimized structures were calculated at the B3LYP/6-31G(d) level of theory while relative enthalpies obtained with G3MP2B3 computational protocol are depicted in grey color. 

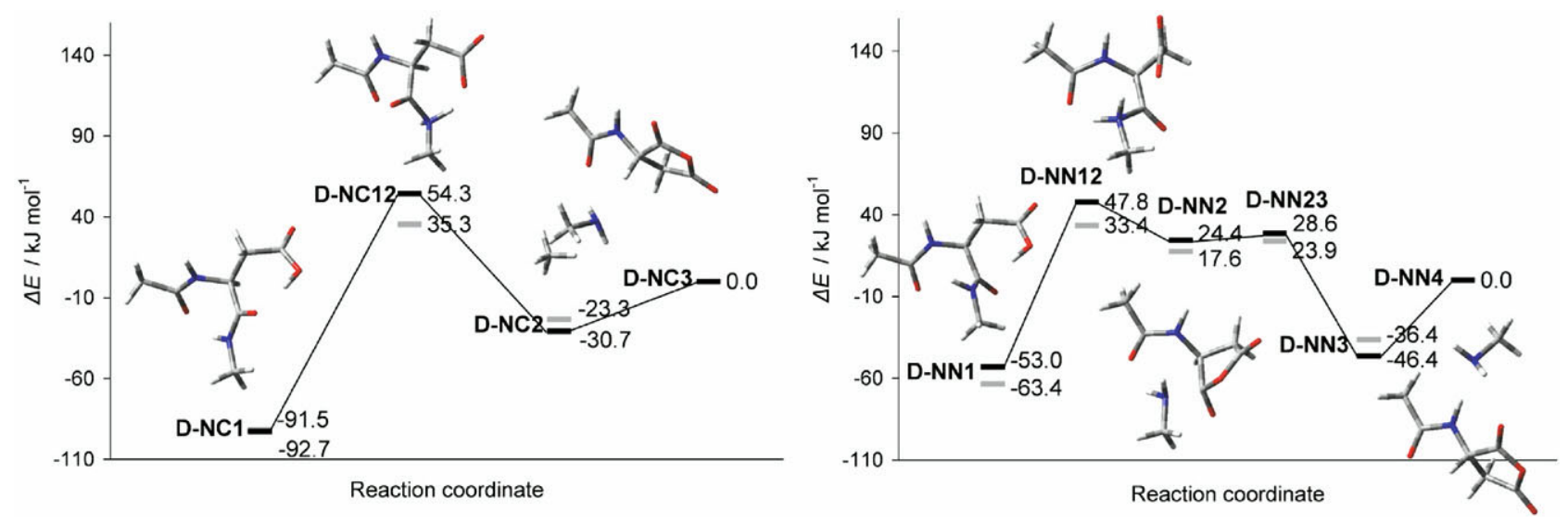

Figure 4. Schematic representation of the mechanisms D-NC and D-NN potential energy profiles. The relative energies and optimized structures were calculated at the B3LYP/6-31G(d) level of theory while relative enthalpies obtained with G3MP2B3 computational protocol are depicted in grey color.

bond formation (between deprotonated carboxylic group and carbon atom of the backbone carbonyl), and peptide bond cleavage. An additional intermediate (DNN2) and corresponding transition-state (D-NN23) exist in the potential energy profile of the D-NN mechanism. However, corresponding minima in the D-NC mechanism were not located because either following of the reaction path in a flat part (where is not so reliable) failed or a reaction path branching occurred. The question arises whether reaction products are formed directly (from transition-state(s) D-NC12 or D-NN12, respectively), or through depicted intermediate(s) (DNC2 or D-NN3) which then dissociate to final products. Although this work does not provide such answers, it indicates that in both cases neither high-energy intermediates nor transition states exist, i.e., the reaction threshold is not changed.

Summarizing the results, these mechanisms seems to be endothermic. Mechanism C threshold is almost twice the threshold for mechanism D. Roughly speaking, during CID process intermediate C-NC2 (or C-NN2) can be equally formed as intermediate D-NC2 (or D-NN2) but the high dissociation threshold for the second step in mechanism $C$ favors mechanism D. However, if sufficient energy is transferred, both mechanisms may be operative. Energies employed in low-energy CID were in the range of 2 to $3.5 \mathrm{eV}$ (190 to $330 \mathrm{~kJ} \mathrm{~mol}^{-1}$ ) [6], see Methods [21]. These energies are sufficient to cross reaction barriers for both mechanisms. However, during CID translational energy is transferred into internal, vibrational, and rotational states of peptide ion, which then undergoes dissociation. Energy-transfer efficiency depends on several factors: initial translational energy, size of peptide, mass of collisional gas atom. For $(\mathrm{Gly})_{4}$ (impact parameter of $0 \AA$ ) it is found that 60 to $70 \%$ of CID energy is transferred to a folded structure, while 55 to $65 \%$ is transferred to an

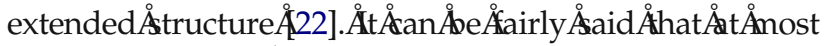
160 to $200 \mathrm{~kJ} \mathrm{~mol}^{-1}$ is transferred into internal vibrational states of analyzed peptide. That amount of energy exceeds dissociation limits in both mechanisms. However, the same study shoved that more than $80 \%$ of transferred energy corresponds to peptide torsional modes, while the energy transferred to heavy atom-hydrogen stretch is negligible $(<1 \%)$. The imaginary frequencies of mechanism D transition states (D-NC12 $265.7 \mathrm{i} \mathrm{cm}^{-1}$ and DNN12 $102.4 \mathrm{i} \mathrm{cm}^{-1}$ ) both correspond to torsional movement. On the other hand, mechanism $\mathrm{C}$ transition-state imaginary frequencies (C-NC23 $1644.8 \mathrm{i} \mathrm{cm}^{-1}$ and C-NN34 $1663.7 \mathrm{i} \mathrm{cm}^{-1}$ ) correspond solely to $\mathrm{H}$ stretch between hydroxylic oxygen and amide nitrogen. With all this in mind, it seems that aspartic acid selective cleavage proceeds through mechanism D.

\section{Conclusions}

Experimental and theoretical results showed that $\mathrm{H} / \mathrm{D}$ exchange of the $\mathrm{AspH}^{+}$and $\mathrm{GluH}^{+}$side-chain carboxylic hydrogen is mainly result of "flip-flop" mechanism. That conclusion supports the possibility of a side-chain carboxylic group proton transfer, which initiates a simultaneous bond formation to one of its oxygens. This is consistent with the idea that the backbone carboxylic proton is "locally mobile" and may potentially initiate selective cleavage of the amide bond ("aspartic acid effect"). The corresponding mechanistic study suggests the process to proceed by a complex one-step mechanism including proton transfer (from side-chain carboxylic group to backbone amide group), bond formation (between deprotonated carboxylic group and carbon atom of the backbone carbonyl), and peptide bond cleavage.

\section{Acknowledgments}

The author acknowledges helpful discussions with Nađa Došlić, Leo Klasinc, David M. Smith, and Dunja Srzić. This work was suspported by the Ministry of Science, Education, and Sports of the Republic of Croatia and the Croatian Academy of Sciences and Arts Foundation. 


\section{Appendix}

Table 1. The B3LYP/6-31G(d) energies (in $E_{\mathrm{h}}$ ) and relative stabilities (in $\mathrm{kJ} \mathrm{mol}^{-1}$ ) of model system $\mathrm{CH}_{3} \mathrm{CO}-\mathrm{Asp}$ $\mathrm{NHCH}_{3}$ mechanisms $\mathrm{C}$ and D structures

\begin{tabular}{|c|c|c|c|c|c|}
\hline Structure & $E$ & $\Delta$ & Structure & $E$ & $\Delta$ \\
\hline C-NNO & -684.426059 & -106.3 & $\mathrm{C}-\mathrm{NC} 1$ & -684.420885 & -92.7 \\
\hline C-NN1 & -684.426660 & -107.9 & C-NC12 & -684.368082 & 45.9 \\
\hline C-NN12 & -684.364905 & 54.3 & C-NC2 & -684.389942 & -11.5 \\
\hline C-NN2 & -684.386022 & -1.2 & C-NC23 & -684.340463 & 118.4 \\
\hline C-NN23 & -684.382179 & 8.9 & C-NC3 & -684.396402 & -28.4 \\
\hline C-NN3 & -684.388792 & -8.5 & C-NC4 & -684.385568 & 0.0 \\
\hline C-NN34 & -684.330625 & 144.3 & & & \\
\hline C-NN4 & -684.402209 & -43.7 & & & \\
\hline C-NN5 & -684.385568 & 0.0 & & & \\
\hline D-NN1 & -684.405764 & -53.0 & D-NC1 & -684.420885 & -92.7 \\
\hline D-NN12 & -684.367369 & 47.8 & D-NC12 & -684.364880 & 54.3 \\
\hline D-NN2 & -684.376268 & 24.4 & D-NC2 & -684.397259 & -30.7 \\
\hline D-NN23 & -684.374674 & 28.6 & D-NC3 & -684.385568 & 0.0 \\
\hline D-NN3 & -684.403225 & -46.4 & & & \\
\hline D-NN4 & -684.385568 & 0.0 & & & \\
\hline
\end{tabular}

Table 2. The G3MP2B3 enthalpies (in $E_{\mathrm{h}}$ ) and relative stabilities (in $\mathrm{kJ} \mathrm{mol}^{-1}$ ) of model system $\mathrm{CH}_{3} \mathrm{CO}-\mathrm{Asp}-\mathrm{NHCH}_{3}$ mechanisms $\mathrm{C}$ and D structures

\begin{tabular}{lrrlr}
\hline Structure & $H(298 K)$ & \multicolumn{1}{c}{$\Delta$} & Structure & \multicolumn{1}{c}{$H(298 K)$} \\
\hline \hline C-NN0 & -683.487141 & -106.4 & C-NC1 & -683.481497 \\
C-NN1 & -683.486769 & -105.4 & C-NC12 & -683.432258 \\
C-NN12 & -683.430294 & 42.9 & C-NC2 & -683.459504 \\
C-NN2 & -683.456350 & -25.5 & C-NC23 & -683.409552 \\
C-NN23 & -683.452968 & -16.6 & C-NC3 & -683.457987 \\
C-NN3 & -683.460016 & -35.1 & C-NC4 & -683.446630 \\
C-NN34 & -683.403352 & 113.6 & & -33.8 \\
C-NN4 & -683.461092 & -38.0 & & -29.8 \\
C-NN5 & -683.446630 & 0.0 & & -6.0 \\
D-NN1 & -683.470796 & -63.4 & D-NC1 & -683.481497 \\
D-NN12 & -683.433914 & 33.4 & D-NC12 & -683.433168 \\
D-NN2 & -683.439920 & 17.6 & D-NC2 & -683.455522 \\
D-NN23 & -683.437527 & 23.9 & D-NC3 & -683.446630 \\
D-NN3 & -683.460507 & -36.4 & & -91.5 \\
D-NN4 & -683.446630 & 0.0 & & -23.3 \\
\end{tabular}

\section{References}

1. Paizs, B.; Suhai, S. Fragmentation Pathways of Protonated Peptides. Mass Spectrom. Rev. 2005, 24, 508-548.

2. Burlet, O.; Yang, C. Y.; Gaskell, S. J. Influence of Cysteine to Cysteic Acid Oxidation on the Collision-Activated Decomposition of Protonated Peptides-Evidence for Intraionic Interactions. J. Am. Soc. Mass Spectrom. 1992, 3, 337-344

3. Yu, W.; Vath, J. E.; Huberty M. C.; Martin, S. A. Identification of the Facile Gas-Phase Cleavage of the Asp-Pro and Asp-Xxx Peptide-Bonds in Matrix-Assisted Laser-Desorption Time-of-Flight Mass-Spectrometry. Anal. Chem. 1993, 65, 3015-3023.

4. Price, W. D.; Schnier P. D.; Jockush R. A.; Williams, E. R. Unimolecular Reaction Kinetics in the High-Pressure Limit Without Collisions. J. Am. Chem. Soc. 1996, 118, 10640-10644.

5. Gu, C. G.; Tsaprailis, G.; Breci, L.; Wysocki, V. H. Selective Gas-Phase Cleavage at the Peptide Bond Terminal to Aspartic Acid in FixedCharge Derivatives of Asp-Containing Peptides. Anal. Chem. 2000, 72, 5804-5813.

6. Tsaprailis, G.; Somogyi, A.; Nikolaev E. N.; Wysocki, V. H. Refining the Model for Selective Cleavage at Acidic Residues in Arginine-Containing Protonated Peptides. Int. J. Mass Spectrom. 2000, 195/196, 467-479.

7. Paizs, B.; Suhai, S.; Hargittai, B.; Hruby, V. J.; Somogyi, A. Ab Initio and MS/MS Studies on Protonated Peptides Containing Basic and Acidic Amino Acid Residues: I. Solvated Proton versus Salt-Bridged Structures and the Cleavage of the Terminal Amide Bond of Protonated RD-NH Int. J. Mass Spectrom. 2002, 219, 203-232.
8. Grewal, R. N.; El Aribi, H.; Harrison A. G.; Siu K. W. M.; Hopkinson, A. C. Fragmentation of Protonated Tripeptides the Proline Effect Revisited. J. Phys. Chem. B 2004, 108, 4899-4908.

9. Herrmann, K. A.; Wysocki, V. H.; Vorpagel, E. R. Computational Investigation and Hydrogen/Deuterium Exchange of the Fixed Charge Derivative Tris(2,4,6-Trimethoxyphenyl) Phosphonium: Implications for the Aspartic Acid Cleavage Mechanism. J. Am. Soc. Mass Spectrom. 2005, 16, 1067-1080.

10. Bartmess, J. E.; Georgiadis, R. M. Empirical Method for the Determination of Ion Gauge Sensitivities to Different Gases. Vacuum 1983, 33, 149-153.

11. Wyttenbach, T.; Bowers, M. T. Gas Phase Conformations of Biological Molecules: The Hydrogen/Deuterium Exchange Mechanism. J. Am. Soc. Mass Spectrom. 1999, 10, 9-14.

12. Rožman, M. The Gas-Phase H/D Exchange Mechanism of Protonated Amino Acids. J. Am. Soc. Mass Spectrom. 2005, 16, 1846-1852.

13. Baboul, A. G.; Curtiss, L. A.; Redfern, P. C.; Raghavachari, K. Gaussian-3 Theory Using Density Functional Geometries and ZeroPoint Energies. J. Chem. Phys. 1999, 110, 7650-7657.

14. Frisch, M. J.; Trucks, G. W.; Schlegel, H. B.; Scuseria, G. E.; Robb, M. A.; Cheeseman, J. R.; Montgomery, J. A., Jr.; Vreven, T.; Kudin, K. N.; Burant, J. C.; Millam, J. M.; Iyengar, S. S.; Tomasi, J.; Barone, V.; Mennucci, B.; Cossi, M.; Scalmani, G.; Rega, N.; Petersson, G. A.; Nakatsuji, H.; Hada, M.; Ehara, M.; Toyota, K.; Fukuda, R.; Hasegawa, J.; Ishida, M.; Nakajima, T.; Honda, Y.; Kitao, O.; Nakai, H.; Klene, M.; Li, X.; Knox, J. E.; Hratchian, H. P.; Cross, J. B.; Adamo, C.; Jaramillo, J.; Gomperts, R.; Stratmann, R. E.; Yazyev, O.; Austin, A. J.; Cammi, R.; Pomelli, C.; Ochterski, J. W.; Ayala, P. Y.; Morokuma, K.; Voth, G. A. Salvador, P.; Dannenberg, J. J.; Zakrzewski, V. G.; Dapprich, S.; Daniels, 
A. D.; Strain, M. C.; Farkas, O.; Malick, D. K.; Rabuck, A. D.; Raghavachari, K.; Foresman, J. B.; Ortiz, J. V.; Cui, Q.; Baboul, A. G.; Clifford, S.; Cioslowski, J.; Stefanov, B. B.; Liu, G.; Liashenko, A.; Piskorz, P.; Komaromi, I.; Martin, R. L.; Fox, D. J.; Keith, T.; Al-Laham, M. A.; Peng, C. Y.; Nanayakkara, A.; Challacombe, M.; Gill, P. M. W.; Johnson, B.; Chen, W.; Wong, M. W.: Gonzalez, C.; Pople, J. A. Gaussian 03, Revision B.05; Gaussian, Inc.: Pittsburgh PA, 2003.

15. Rožman, M.; Srzić, D.; Klasinc, L. Gas-Phase Interaction of Protonated Lysine with Water. Int. J. Mass Spectrom. 2006, in press.

16. Campbell, S.; Rodgers, M. T.; Marzluff, E. M.; Beauchamp, J. L. Deuterium Exchange as Probe of Biomolecule Structure. Fundamental Studies of Gas-Phase H/D Exchange Reactions of Protonated Glycine Oligomers with $\mathrm{D}_{2} \mathrm{O}, \mathrm{CD}_{3} \mathrm{OD}, \mathrm{CD}_{3} \mathrm{CO}_{2} \mathrm{D}$, and $\mathrm{ND}_{3}$. J. Am. Chem. Soc. $1995,117,12840-12854$

17. Green, M. K.; Lebrilla, C. B. Ion-Molecule Reactions as Probes of Gas-Phase Structures of Peptides and Proteins. Mass Spectrom. Rev. 1997, 16, 53-71.
18. He, F.; Marshall, A. G. Weighted Quasi-Newton and Variable-Order, Variable-Step Adams Algorithm for Determining Site-Specific Reaction Rate Constants. J. Phys. Chem. A 2000, 104, 562-567.

19. Sun, W.; Kinsel, G. R.; Marynick, D. S. Computational Estimates of the Gas-Phase Basicity and Proton Affinity of Glutamic Acid. J. Phys. Chem A 1999, 103, 4113-4117.

20. Rožman, M.; Bertoša, B.; Klasinc, L.; Srzić, D. Gas-Phase H/D Exchange of Sodiated Amino Acids: Why do we see zwitterions? J. Am. Soc. Mass Spectrom. 2006, 17, 29-36.

21. Levisetti, M. G.; Suri, A.; Vidavsky, I.; Gross, M. L.; Kanagawa, O.; Unanue, E. R. Autoantibodies and CD4 T cells target a $\beta$-cell retroviral envelope protein in nonobese diabetic mice. Int. Immunol. 2003, 15, 1473-1483.

22. Meroueh, O.; Hase, L. W. Energy Transfer Pathways in the Collisional Activation of Peptides. Int. J. Mass Spectrom. 2000, 201, 233-244. 